\title{
Dilemma, Reform and Outlet: Reflections on Inclusive Education of Autism
}

\author{
Zhu Yuanyuan
}

School of Arts and Law, Wuhan University of Technology, Wuhan 430070, China

$$
\text { 362104558@qq.com }
$$

\begin{abstract}
Inclusive education has developed into the mainstream of the development of special education in the world. China has advocated inclusive education for many years, but the implementation of inclusive education for autistic children is still not optimistic. The inclusive education to autistic children faced with many dilemmas: the lack of special education resources, the absence of government policy and law, social discrimination and prejudice. As increased attention to autistic children and the beneficial exploration, the dilemma will has some outlets: promoting of small class teaching, developing IEP (individualized education plan) if persist in "supported by government, promoted by school, cared by society".
\end{abstract}

Keywords: inclusive education; autism; dilemma; outlet

\section{Introduction}

Inclusive education refers to the education of children with disabilities into the general education to the maximum extent, making disabled children accept education with ordinary children in ordinary schools. At present, most of the children who receive special education are visual disability, hearing disability, and some children with limb disability. Autism belongs to the category of mental disability. Autistic children has obstacles in social interaction, language communication and other aspect, so receive education in general schools is more important than other disabled children. However, for various reasons, inclusive education of autistic children is difficult and many children back to special schools or drop out at home from ordinary schools.

\section{Dilemma}

The main environment for the rehabilitation of autistic children is the isolated pre-school rehabilitation centers or special schools, and let the children return to the general education environment is almost the wish of all parents of children with autism. However, inclusive education of autistic children is facing the following dilemmas:

\subsection{Ordinary schools lack of special education resources}

According to the Compulsory Education Law and the Special Education Promotion Plan, every child has the right to receive compulsory education. But because ordinary schools cannot provide autistic children with special education services and have difficulty in making tailored education program for each autistic child. So it's difficult for autistic children to accept the real inclusive education in normal schools.

In January 2014, the Special Education Promotion Plan (2014-2016), put forward "arrange disabled students 'learning in regular class' in ordinary schools as much as possible, strengthen the construction of resource room of special education". ${ }^{[1]}$ Although "learning in regular class" has been carried out for many years, but in a considerable number of schools, the form is greater than the meaning. As the survey found that, on the one hand, the utilization rate of resources classroom in part of the school is not ideal. Some combined used with psychological counseling room, and others have not been used, the equipment is very new. On the other hand, "learning in regular class" is only "sitting in regular class". Because the autistic children enrolled in the class is not included in 
the assessment, many autistic children sitting in the last row where the teacher ignored. Many autistic children finally returned to special education schools after a period of study, because it is difficult to integrate.

\subsection{Teachers lack of understanding and professional skills}

First, there is almost no study of inclusive education and special education in the teachers of ordinary school in our country. More than half of the teachers have not heard of inclusive education. Only a small number of teachers get the relevant knowledge through their own learning or training, but the proportion is less than $15 \%$. In developed countries such as Britain and America, inclusive education is a compulsory course for all normal students. However, $81 \%$ of the teachers in our country have never studied inclusive education before graduation.

Second, there are contradictions in the understanding of inclusive education between the parents and the ordinary school and its teachers. Most parents want to let their children into ordinary schools to receive inclusive education, so that they can better integrate into society. However, more than half of the school administrators and $80 \%$ of teachers think that special children should go to a special school. Many schools and teachers will shut autistic children out from the beginning. Even if the autistic children can be enrolled, they will be persuaded to leave school once they can not adapt or other parents protest.

Third, teachers lack of patience and attention for autistic students' education. If schools and teachers are only concerned about the rate of admission and top students, autistic children are likely to be abandoned. Autism is a mental disability and prone to emotional disorders, which require the attention of teachers and timely comfort. Especially in adolescence, autistic children will have trouble in behavior if they lack of attention. Therefore, the teacher's sense of responsibility and patience may have a direct impact on a child with autism to stay in the ordinary school or not.

Fourth, autistic children lack of professional and individualized education support in the curriculum. Children with mild autism have no problem in ordinary school and the key is whether they can be provided individualized education. It is very difficult to meet the needs of the individualized teaching and the professional teachers. In most ordinary school, the position of resources teachers took on by other teachers who do not have the background of special education.

\subsection{Lack of relevant laws and regulations}

The lack of relevant laws and regulations has also caused the current situation of special education in China. Autism has been included in the category of mental disability. All the policies and laws applicable to persons with disabilities in our country are also applicable to children with autism. Although China has the Law on the protection of persons with disabilities and Interim rules for special education schools, have not relevant rules and regulations for IEP (individualized education plan) implementation, not on the special education act specific rules promulgated. For autistic children, our country has no special laws and regulations to protect. ${ }^{[2]}$

\section{Reform}

\subsection{Foreign, Hong Kong, Macao and Taiwan experience}

In Hong Kong, in accordance with the law, ordinary schools can not refuse educational requirements of special children, and should provide barrier free education conditions according to the relevant guidelines, provide help in curriculum design, examination arrangements etc. If ordinary schools receive special children, the Hong Kong Ministry of Education will grant subsidies for the recruitment of special education teachers to develop inclusive education. In addition, the Hong Kong Ministry of Education will also help ordinary school teachers to receive special education and training in college, and now $15 \%$ of the ordinary school teachers have completed the 
training. Hong Kong has also set up "a working group serviced for autism”, long-term commitment to the development and implementation of integrated education.

In foreign countries, the United States in 1975 promulgated the Education Law clearly defined that all public schools must formulate IEP (individualized education plan) for children with special needs. The purpose is to make these children return to the classroom in the future and solve the existing difficulties in the teaching of special education. Canada, Australia, the United Kingdom and some other countries also write IEP into law and enforce it. In Taiwan, IEP has been incorporated into the law, such as the Taiwan special education law enforcement rules.

\subsection{The advanced domestic practice}

In April 2012, the implementation of the Guangdong special children and adolescents enrolled in the classroom teaching resources construction and management measures promulgated and implemented. Since the beginning of September 2012, 20 primary and secondary schools in Guangzhou have become the pilot schools, where teachers from two public special education schools regularly visit to guide teaching. ${ }^{[3]}$

In 2015, Nanjing became the "national reform experimentation area in special education", has established 44 experimental schools, including 33 primary schools, 5 junior middle schools, 6 kindergartens. ${ }^{[4]}$

In May 1, 2017, the newly revised Regulation on the Education of the Disabled will implement, which propose to " actively promote the inclusive education" "give priority to general education", further defined the development direction of China's education of disabled people. ${ }^{[5]}$

\section{Outlet}

The above experience and exploration provide a way out for the current dilemma of autistic children.

\subsection{Improve government policies, laws and regulations}

First, formulate and improve relevant policies. Inclusive education, especially autistic children's education, the existing support policies are less, should be developed. First of all, strengthen the construction of support system in special education. In the leading of the education authorities combined with the relevant departments, integrating special education into the government management system to ensure "the input of funds, the construction of facilities and availability of teachers". Provinces, autonomous regions, municipalities directly under the central government, as well as a number of conditional municipalities with districts establish special education resource centers to promote the work of "learning in regular class" relying on special education schools in the region. At the same time, set up a team of doctors, psychologists and other experts through the special education resource center and organize social workers and volunteers to join them. Secondly, the education authorities take the lead to solve the problem in enrollment of autistic children by use of a variety of national support policies, select some schools as pilot schools to carry out the inclusive education, provide the autistic children with necessary education resources and government's education subsidy.

Second, establish and improve laws and regulations. First of all, the NPC and its Standing Committee amend the supplementary provisions of the Compulsory Education Law to further clarify the autistic children as a statutory object of special education, and write the IEP (individualized education plan / program) into the law. Secondly, the Department of education formulates relevant regulations and implementation details to further clarify the education of autistic children and other special children. Relevant departments should step up the development of admission assessment criteria for autistic children, and be brought into the public. At the same time, 
regularly monitor the condition of autistic children to ensure that eligible autistic children can timely receive the inclusive education.

\subsection{Increase the support of special education resources}

First, the government should set up a special education resource center to build a professional teaching staff and train a group of expert teachers. Special education schools should rely on the special education resources center to achieve functional transformation. Special education resource centers and special education schools should cooperate with each other to strengthen cooperation. On the one hand, both of the professional teachers go to the pilot school to carry out tour guidance teaching regularly. On the other hand, both of them provide professional training support for inclusive education of ordinary schools, and help ordinary teachers overcome the "skill panic".

Second, strengthen the special education knowledge and ability of teachers. Ordinary schools should have the ability to educate autistic children. In the developed countries, inclusive education is a compulsory course for all normal students. ${ }^{[5]}$ Therefore, open inclusive education course and related courses as required courses in normal college is necessary. With the standard whether or not received special education before, the teacher should continue to accept the professional skills training and guidance of different levels from the teachers in special education resource center and special education schools after they enters the ordinary school. At least $10 \%$ of ordinary school teachers should receive professional skill training of special education. The training, implementation and implementation effect of the teachers in special education and inclusive education included in the annual assessment index and term performance evaluation index.

Third, provide suitable and feasible teaching for autistic children. First of all, promote small class teaching where possible. Foreign teacher-student ratio of an inclusive education class can reach 1:15, or even 1:2. In view of the actual situation in our country, we can consider establishing several small classes of 20 or 30 people in every grade, each of which contains less than 3 of autistic students. The selection of the ordinary students comes from voluntary enrollment and random distribution. Small class teaching can make autistic children receive more personalized attention, so that teachers will have a lot of time to observe, and do individualized teaching programs for different autistic children. Secondly, implement the combined system of large classes and small classes in the place lack of the ability and conditions to carry out small class teaching. That is, cultural classes of the autistic children can be taught in small classes together by special education teachers, and sports, labor classes of autistic students can be taught in large classes with ordinary students. Thirdly, set up the course about survival skills and life skills for autistic children. In view of the parents of autistic children worry about their children's survival skills as well as skills teaching effect is not ideal at past, the skills teaching for autistic children should be treated as the same important as cultural knowledge teaching. Survival skills and life skills must be taught, such as manual, cooking, life lessons. Teaching should pay attention to repetition and patience, because autistic children often can not understand by taught at a time.

\subsection{Abandon social discrimination and prejudice}

First, strengthen propaganda and guidance, abandon the wrong idea. Many people, including teachers, have more or less discrimination and prejudice against autism before deeply touch and understand it. Autistic children usually are thought has parenting problems and psychological problems which will potentially affect and threaten the physical and mental health of ordinary children. However, autism is a congenital and there is no direct relationship between autism and family upbringing. An autistic child who recovered well also can go to school, go to work and get married like a normal person. In addition, autistic children have a number of advantages in the work, such as diligent, discipline, dedication, patience for simple repeated operation. 
Second, open mind, achieve win-win. Inclusive education is proposed and implemented for special children with disabilities at the first. However, if the school and the teacher can guide correctly and reasonably, ordinary parents can open their minds, give more understanding and tolerance, ordinary children will also benefit from the inclusive education. Abroad, there are many parents are willing to send their children to an inclusive environment including special children, and sometimes even queue up to apply. The inclusive education that we advocate should be two-way and mutual integration. On the one hand, autistic children can be integrated into ordinary children's environment. On the other hand, ordinary children can be integrated into the special children's environment. If autistic children study in the ordinary school, not only conducive to their recovery and integration into society, but also make the other ordinary children more inclusive. If ordinary children can really accept autistic children, they can be inspired the good and love in deep heart as well as know how to shoulder social responsibility. This is a good opportunity to educate normal children and is benefit to their growth. Therefore, only in the true mutual integration can achieve a win-win education.

\section{Conclusions}

Autistic children are also known as "children of the stars". They are like stars in the sky which seems very far away but is actually around us with the increasing incidence year by year. Autistic children's core obstacle is social, so they are more urgent to learn in ordinary schools in the first step in life. In face of the dilemma of inclusive education to autistic children, we should persist in "supported by government, promoted by school, cared by society", improve government policies, and laws, strengthen support of the special education resources, abandon the social discrimination and prejudice, and finally create a tolerant social environment of integration to realize the true fusion.

\section{Acknowledgement}

Thanks my tutor for providing the information of the meeting and his supervision and guidance on the paper writing. Thanks my seniors for their patient help and advice. This paper is supported by the project of Research on the teaching methods of law and reformation of quality education in Universities of technology (2014107).

\section{References}

[1] Information on http://www.gov.cn/xxgk/pub/govpublic/mrlm/201401/t20140118_66612.html

[2] Reporter Ge Liangliang, Zhang Shuo: Inclusive education difficulties how to work together to crack the submitted to People's Daily (2016)

[3] Reporter Zhao Xinxing: Autistic children integrated education dilemma submitted to Southern Daily (2012)

[4] Information on http://www.gov.cn/zhengce/content/2017-02/23/content_5170264.htm

[5] Xu Yun, Zhu Minrui: The "pain" and "difficulty" of inclusive education for autistic children in China submitted to Modern Special Education (2016) 